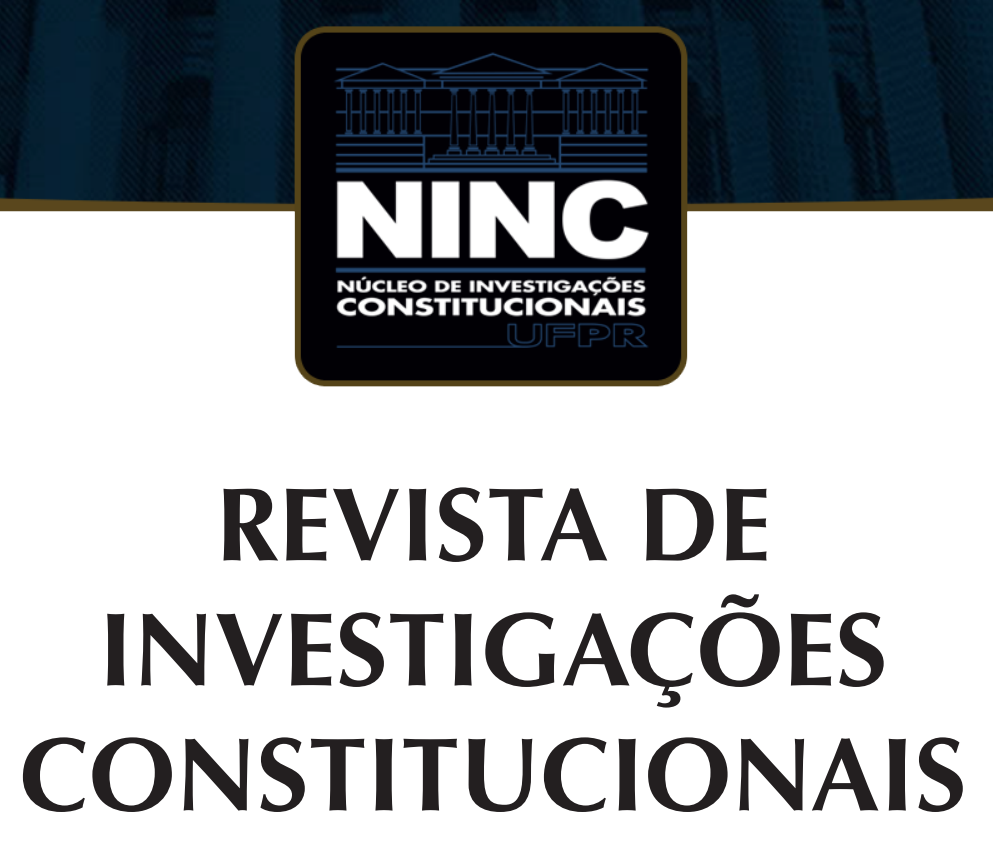

JOURNAL OF CONSTITUTIONAL RESEARCH

vol. 6 | n. 3 | setembro/dezembro 2019 | ISSN 2359-5639 | Periodicidade quadrimestral Curitiba | Núcleo de Investigações Constitucionais da UFPR | www.ninc.com.br 


\title{
La tutela jurisdiccional efectiva con relación al derecho a ser juzgado dentro de un plazo razonable en procedimientos tributarios: experiencia comparada entre Chile y Brasil frente a la Convención Americana de Derechos Humanos
}

\section{The effective jurisdictional protection with relation to the right to be judged within a reasonable time in tax proceedings: comparative experience between Chile and Brazil in regarding the American Convention on Human Rights}

\author{
ANTONIO FAÚNDEZ-UGALDE 1 , * \\ ' Pontificia Universidad Católica de Valparaíso (Valparaíso, Chile) \\ antonio.faundez@pucv.cl \\ https://orcid.org/0000-0002-1293-1270
}

Recebido/Received: $11.01 .2019 /$ January $11^{\text {th }}, 2019$ Aprovado/Approved: $25.11 .2019 /$ November $25^{\text {th }}, 2019$

Resumen:

El presente artículo aborda el problema de la colisión de derechos fundamentales con relación al derecho a ser juzgado dentro de un plazo razonable en procedimientos tributarios, postulando, como mecanismo de solución, la posibilidad de que el juez prescinda de la ley inconstitucional y sea leal a la Constitución y al derecho internacional en la aplicación de la Convención Americana de Derechos Humanos. Así, el trabajo comenzará con el análisis de mecanismos efectivos de tutela, como derecho fundamental en sí mismo, y su relación con el derecho tributario material en procedimientos tributarios. Luego, se estudiarán casos de colisión normativa con relación al derecho a ser juzgado dentro de un plazo razonable, para finalizar con propuestas de mecanismos de
Abstract:

This article addresses the problem of the collision of fundamental rights in relation to the right to be tried within a reasonable time in tax proceedings, postulating, as a mechanism of solution, the possibility that the judge disregards the unconstitutional law and is loyal to the Constitution and international law in the application of the American Convention on Human Rights. Thus, the study will begin with the analysis of effective guardianship mechanisms, as a fundamental right in itself, and its relationship with the tax law material in tax procedures. Then, cases of normative collision will be studied in relation to the right to be judged within a reasonable period of time, to end with proposals for mechanisms of solution, considering the praxis in relevant judgments of Chilean courts. The methodology to be

Como citar esse artigo/How to cite this article: FAÚNDEZ-UGALDE, Antonio. La tutela jurisdiccional efectiva con relación al de recho a ser juzgado dentro de un plazo razonable en procedimientos tributarios: experiencia comparada entre Chile y Brasil frente a la Convención Americana de Derechos Humanos. Revista de Investigações Constitucionais, Curitiba, vol. 6, n. 3, p. 687-702, set./dez. 2019. DOI: 10.5380/rinc.v6i3.64284.

* Doctor en Derecho por la Pontificia Universidad Católica de Valparaíso (Valparaíso, Chile). E-mail: antonio.faundez@pucv.cl. 
solución, considerando la praxis en sentencias relevantes de tribunales chilenos. La metodología que se seguirá en esta investigación es aquella propia de las ciencias jurídicas, que se traduce en el estudio de la norma jurídica tributaria y sus fundamentos ideológicos, considerando, asimismo, las tres dimensiones de la dogmática jurídica propuesta por Alexy.

Palabras claves: tutela jurisdiccional; colisión de derechos; derecho tributario; derechos fundamentales; Chile. followed in this research is that of the legal sciences, which translates into the study of the tax legal norm and its ideological foundations, also considering the three dimensions of legal dogma proposed by Alexy.

Keywords: jurisdictional protection; collision of rights; tax law; fundamental rights; Chile.

\section{SUMARIO}

1. Introducción; 2. Tutela jurisdiccional efectiva y derecho material; 3. Colisión normativa frente al derecho a ser juzgado dentro de un plazo razonable; 4. Mecanismos de solución frente a la colisión normativa; 5. Tres sentencias; $\mathbf{6}$. Conclusiones; 7 . Referencias.

\section{INTRODUCCIÓN}

La intervención jurisdiccional debe ser ejercida a través de un proceso que ofrezca un mínimo de garantías para las partes, situación que reviste importancia frente a la función del juez en la aplicación de las normas. Así, en todo proceso, la tutela jurisdiccional se presenta como el derecho de toda persona a que se haga justicia, a que cuando pretenda algo de otra, esta pretensión sea atendida por un órgano jurisdiccional, a través de un proceso con garantías mínimas ${ }^{1}$. Por su parte, De Oliveira ${ }^{2}$ define tutela jurisdiccional como el resultado de la actividad desarrollada por los órganos del Estado que ejercen la jurisdicción o que están autorizados para ello, con miras a la protección del patrimonio jurídico.

Sin embargo, reconocer el derecho a una tutela jurisdiccional no es suficiente sino se encamina a su efectividad en su aplicación. Así, Marinoni ${ }^{3}$ sostiene que la efectividad de la tutela jurisdiccional radica en que debe ser oportuna $y$, en algunos casos, tener la posibilidad de ser preventiva. Es por esta razón que la tutela jurisdiccional efectiva en todo procedimiento tributario no limita su contenido en el derecho a acceder a un tribunal de justicia, sino que involucra, asimismo, el reconocimiento de garantías que impliquen un trato igualitario entre las partes del proceso, sea en virtud del derecho a presentar o debatir un acto de la autoridad fiscalizadora, sea el derecho de las partes de rendir prueba para acreditar sus pretensiones, o bien, garantizar el pronunciamiento del juez tributario dentro de un plazo razonable, como también, el derecho a obtener el cumplimiento de la sentencia o el restablecimiento del imperio del

GONZÁLEZ, Jesús. El derecho a la tutela jurisdiccional. Madrid: Civitas, 1984. p. 29.

DE OLIVEIRA, Carlos. Teoría y práctica de la tutela jurisdiccional. Lima: Communitas, 2008. pp. 176-177.

MARINONI, Luiz. Derecho fundamental a la tutela jurisdiccional efectiva. Lima: Palestra, 2007. p. 220. 
derecho ${ }^{4}$. De Oliveira ${ }^{5}$ indica que hay tutela incluso cuando se desestima lo pedido, ya que, en este caso, quedará protegida la posición sustancial del demandado. No obstante lo anterior, desde ya se hace presente, que la tutela jurisdiccional no queda radicada solamente en los derechos fundamentales, sino que, además, comprende la protección de derechos que no tienen un asidero constitucional ${ }^{6}$.

Ahora bien, dentro de las distintas formas de tutela jurisdiccional", esta investigación tendrá como principal foco de estudio: el derecho a ser juzgado en un plazo razonable, derecho fundamental consagrado en el no 1 del artículo 8 de la Convención Americana de Derechos Humanos $(\mathrm{CADH})^{8}$. Si bien, "la más básica forma de tutela de los derechos está constituida por la propia norma del derecho material"9 , nos hacemos partícipe de los que postulan que la protección de los derechos no puede quedar limitada a normas de derecho tributario material, sino que el proceso también constituye un mecanismo efectivo de tutela ${ }^{10}$. Por lo tanto, si bien el proceso es autónomo en relación 4 Vallespín indica que "[e]l derecho a la tutela judicial efectiva que consagra el art. 24 CE [Constitución es-
pañola de 1978] no agota su contenido en la exigencia de que el interesado tenga acceso a los Tribunales de
Justicia", agrega que se "[e]xige también que el 'fallo se cumpla' y que el recurrente sea puesto en su derecho
y compensado" (VALLESPÍN, David. El modelo constitucional de juicio justo en el ámbito del proceso civil.
Barcelona: Atelier, 2002. pp. 142-143). González precisa que como norma general las violaciones del derecho
a la tutela jurisdiccional se producirán en un proceso y procederán de un órgano jurisdiccional (GONZÁLEZ,
Jesús. El derecho a la tutela jurisdiccional. Madrid: Civitas, 1984. p. 146).

5 DE OLIVEIRA, Carlos. Teoría y práctica de la tutela jurisdiccional. Lima: Communitas, 2008. p. 177.

6 En este sentido se puede citar: MARINONI, Luiz. Derecho fundamental a la tutela jurisdiccional efectiva. Lima: Palestra, 2007. p. 279. Aldunate plantea la problemática en la protección de derechos que carecen el reconocimiento constitucional, los que deberían quedar vinculados al reconocimiento que un juez pueda realizar considerando la ley o vías procesales reguladas por la ley (ALDUNATE, Eduardo. Derechos Fundamentales. Santiago: Legal Publishing, 2008. p. 205)

7 El autor De Oliveira clasifica la tutela jurisdiccional en: (i) tutela declarativa: aquella que tiene por finalidad certificar la existencia de determinada relación jurídica, otorgándole certeza; (ii) tutela condenatoria: aquella que tiene por finalidad satisfacer la obligación de pagar; (iii) tutela constitutiva: tiene por finalidad satisfacer los derechos potestativos; $y$, (iv) tutela ejecutiva lato sensu: tiene por finalidad satisfacer obligaciones de dar y los deberes de constituir (DE OLIVEIRA, Carlos. Teoría y práctica de la tutela jurisdiccional. Lima: Communitas, 2008. p. 218).

$8 \quad$ Si bien partimos de la base de que los textos Constitucionales de cada Estado deben ser complementados con lo dispuesto en los tratados internacionales, asumimos que no es un tema pacífico. En tal sentido, nuestro trabajo no se hará cargo de dicha discusión doctrinaria sobre la jerarquía de los tratados sobre Derechos Humanos en el derecho interno, lo que podría exceder de los límites que se proponen. Un mayor análisis sobre este punto se puede consultar: HENRÍQUEZ, Miriam. Análisis jurisprudencial de la aplicación de los tratados de derechos humanos en recursos de protección (1989 - 2010). Estudios Constitucionales, Talca, vol. 8, n. 2, pp. 745-762. 2010. DOI: http://dx.doi.org/10.4067/S0718-52002010000200022.

9 MARINONI, Luiz. Derecho fundamental a la tutela jurisdiccional efectiva. Lima: Palestra, 2007. p. 174.

10 En este mismo sentido: VALLESPÍN, David. El modelo constitucional de juicio justo en el ámbito del proceso civil. Barcelona: Atelier, 2002. p. 142; MARINONI, Luiz. Derecho fundamental a la tutela jurisdiccional efectiva. Lima: Palestra, 2007. p. 278; DE OLIVEIRA, Carlos. Teoría y práctica de la tutela jurisdiccional. Lima: Communitas, 2008. p. 176; DE OLIVEIRA, Carlos. El derecho a la tutela jurisdiccional efectiva desde la perspectiva de los derechos fundamentales. Revista de Derecho, Valdivia, vol. 22, n. 1, pp. 185-201. 2009. DOI: http://dx.doi.org/10.4067/S0718-09502009000100009. 
al derecho tributario material, no significa que él pueda ser neutro o indiferente a las distintas situaciones de derecho sustancial.

Es precisamente en este punto en que radica el planteamiento del problema relativo a determinar, en un procedimiento tributario, si se presenta en forma permanente una tensión entre el derecho tributario material y la tutela jurisdiccional efectiva, con relación a la razonabilidad del plazo para ser juzgado. Si bien existe un complemento constante entre el derecho tributario material y la tutela jurisdiccional efectiva, resulta necesario establecer cuál es la esfera de uno y otro para la adecuada aplicación de las normas, especialmente cuando existe antinomia de derechos fundamentales ${ }^{11}$, caso en el cual el juez debe optar por el mejor mecanismo de solución que resguarde en forma preferente los derechos de todas las partes del proceso.

En el siguiente apartado se analizarán los mecanismos efectivos de tutela, como derecho fundamental en sí mismo, y su relación con el derecho tributario material en procedimientos tributarios, para luego dar paso a casos de colisión normativa con relación al derecho a ser juzgado dentro de un plazo razonable. Finalizaremos el estudio con propuestas de mecanismos de solución, considerando la praxis en sentencias relevantes de tribunales chilenos. La metodología que se seguirá en esta investigación es aquella propia de las ciencias jurídicas, que se traduce en el estudio de la norma jurídica tributaria y sus fundamentos ideológicos, considerando, asimismo, las tres dimensiones de la dogmática jurídica propuesta por Alexy ${ }^{12}$, esto es: la analítica, la empírica y la normativa. La analítica trata de las consideraciones sistemáticos-conceptuales sobre el derecho válido, que van desde el análisis de los conceptos fundamentales (por ejemplo, el concepto de norma, de derecho subjetivo, de libertad y de igualdad), pasando por la construcción jurídica (por ejemplo, la de la relación entre el supuesto de hecho y las restricciones de los derechos fundamentales y la del efecto en terceros) y por el estudio de la estructura del sistema jurídico (por ejemplo, la llamada irradiación de los derechos fundamentales), hasta la cuestión de la fundamentación (por ejemplo, de la ponderación). La dogmática jurídica empírica tiene un doble significado: primero, el conocimiento del derecho positivamente válido $y$, segundo, de la utilización de premisas empíricas en la argumentación jurídica. Este aspecto de la dimensión empírica alude al conocimiento de los elementos de hecho a ser involucrados, en el sistema de fuentes, como jurídicamente relevantes. Finalmente, la dimensión normativa trata de la orientación y crítica de la praxis jurídica, sobre todo de la praxis de la jurisprudencia

\footnotetext{
11 Se habla de antinomia o colisión de derechos fundamentales cuando el efecto jurídico de la protección iusfundamental alegada por un sujeto (titular del respectivo derecho) es incompatible con el efecto jurídico por otro sujeto a partir de un alegato de protección iusfundamental. El efecto jurídico es que el resultado adjudicado a uno va a implicar negación o rechazo de la protección o amparo defendido por el otro (ALDUNATE, Eduardo. Derechos Fundamentales. Santiago: Legal Publishing, 2008. p. 269).

12 ALEXY, Robert. Teoría de los derechos fundamentales. España: Centro de Estudios Constitucionales. 1993. pp. $29-34$.
} 
judicial; tanto para cerrar las lagunas del material dado autoritativamente, como para abordar el problema de la fundamentación aportada por los tribunales como sustento de sus decisiones.

\section{TUTELA JURISDICCIONAL EFECTIVA Y DERECHO MATERIAL}

Es aceptación generalizada que la protección de los derechos no puede quedar limitada a normas de derecho material, sino que el efectivo mecanismo de tutela se produce por la complementación con un proceso que ofrezca garantías mínimas para las partes ${ }^{13}$.

A mediados del siglo XX, cuando empezó de forma sistemática el estudio de las relaciones entre el proceso y las normas constitucionales, poco se hablaba de la garantía de efectividad. Sin embargo, en estos días, la tutela jurisdiccional, constituyendo en sí misma un derecho fundamental, incide en la efectiva protección de los derechos de las partes en el proceso ${ }^{14}$.

En opinión de Marinoni ${ }^{15}$, el derecho a la tutela jurisdiccional efectiva engloba el derecho a la técnica procesal adecuada; el derecho de participar a través del procedimiento adecuado; $y$, el derecho a la respuesta del juez. Agrega el mismo autor que el derecho a la tutela jurisdiccional efectiva tiene relación, en primer lugar, con la posibilidad de participar y por eso presupone un derecho de participación.

Distintos autores se han manifestado sobre a la relación entre el derecho material y la tutela jurisdiccional, cuya complementación no les resulta indiferente. Marino$\mathrm{ni}^{16}$ indica que el deber de protección requiere, es cierto, reglas de derecho material; el mismo autor sostiene que no hay duda de que el derecho de acción garantiza la tutela jurisdiccional efectiva ${ }^{17}$; de tal forma el derecho de acción, para ser comprendido, debe estar relacionado con las formas de protección jurisdiccional del derecho material ${ }^{18}$. Por su parte, Chiovenda ${ }^{19}$ expresa que se ve una clara separación entre el derecho, como una

13 En este sentido: VALLESPÍN, David. El modelo constitucional de juicio justo en el ámbito del proceso civil. Barcelona: Atelier, 2002. pp. 142-143; MARINONI, Luiz. Derecho fundamental a la tutela jurisdiccional efectiva. Lima: Palestra, 2007. p. 278; DE OLIVEIRA, Carlos. Teoría y práctica de la tutela jurisdiccional. Lima: Communitas, 2008. p. 176.

14 FAÚNDEZ-UGALDE, Antonio. Tutela jurisdiccional efectiva y derecho tributario: ¿Una tensión permanente en el procedimiento de reclamación por vulneración de derechos?. Revista de Estudios Tributarios, n. 5, pp. 207-224. 2011. DOI: https://revistas.uchile.cl/index.php/RET/article/view/41137/42676.

15 MARINONI, Luiz. Derecho fundamental a la tutela jurisdiccional efectiva. Lima: Palestra, 2007. pp. 227228.

16 MARINONI, Luiz. Derecho fundamental a la tutela jurisdiccional efectiva. Lima: Palestra, 2007. p. 278.

17 En el mismo sentido: PÉREZ, Álvaro; SILVA, Oscar. El imperativo de transparencia patrimonial del deudor como requisito funcional para una ejecución civil eficiente. Revista lus Et Praxis, Talca, vol. 15, n. 2, pp. 79-115. 2009. Disponible: http://www.revistaiepraxis.cl/index.php/iepraxis/article/view/180/173.

18 MARINONI, Luiz. Teoría geral do proceso. São Paulo: Revista dos Tribunais. 2006. p. 227.

19 CHIOVENDA, Giuseppe. Istituzioni di diritto processuale civile. Napoli: Jovene. 1960. p. 139. 
expectativa de un bien, y el proceso, como un medio para conseguirlo, independiente de la voluntad del adversario. De Oliveira ${ }^{20}$ indica que para la adecuación de la tutela jurisdiccional para la superación de la crisis sufrida por el derecho material, debe tener la aptitud de realizar la eficacia prometida por el derecho material, con la mayor efectividad y seguridad posibles. Por su parte, Proto ${ }^{21}$ manifiesta que con la elaboración en el siglo XIX y en los primeros años del siglo pasado del derecho de acción, permitió reconciliar, de forma automática y necesaria, el derecho material (todos los derechos materiales) y la tutela jurisdiccional civil, colaborando así para la superación de los límites intrínsecos de la tipicidad de las acciones del derecho romano clásico.

En resumen, los autores coinciden en que la complementación entre el derecho material y el proceso resulta indispensable para una tutela jurisdiccional efectiva. Sin embargo, cabe precisar, que la tutela jurisdiccional siempre estará presente, más no la tutela del derecho propiamente tal, el cual se manifestará en la medida de que la técnica procesal reconozca el derecho material, esto es, cuando la sentencia de lugar al derecho pretendido en la demanda ${ }^{22}$. Marinoni ${ }^{23}$ señala que comprendida la necesidad de tutela de los derechos a través del proceso jurisdiccional, es correcto pensar que el juez y el legislador, al velar por la técnica procesal adecuada a la efectividad de la prestación jurisdiccional, prestan protección a los derechos y, en consecuencia, al derecho fundamental a la tutela jurisdiccional efectiva, los cuales, si no fuesen de esta manera, de nada valdrían.

Habiendo revelado la imperiosa necesidad de complementación entre el proceso y el derecho material, no se desconoce la posibilidad de una tensión permanente entre la tutela jurisdiccional y el derecho tributario material al momento de otorgar una protección efectiva de los derechos. Cabe recordar que la tutela jurisdiccional, en sí misma, constituye un derecho fundamental, y en tal sentido, éste puede entrar en conflicto con el derecho tributario material, lo que se analizará en los próximos planteamientos.

\section{COLISIÓN NORMATIVA FRENTE AL DERECHO A SER JUZGADO DENTRO DE UN PLAZO RAZONABLE}

La circunstancia de que la tutela jurisdiccional efectiva constituya en sí misma un derecho fundamental, surge la posibilidad de que exista una constante tensión con las normas de derecho tributario material. Así, la complementación entre el proceso y el derecho tributario material resulta esencial para una tutela efectiva; sin embargo, es

20 DE OLIVEIRA, Carlos. Teoría y práctica de la tutela jurisdiccional. Lima: Communitas, 2008. p. 221.

21 PROTO, Andrea. Lezioni di diritto processuale civile. Napoli: Jovene. 2006. p. 51.

22 MARINONI, Luiz. Derecho fundamental a la tutela jurisdiccional efectiva. Lima: Palestra, 2007. pp. 174175.

23 MARINONI, Luiz. Derecho fundamental a la tutela jurisdiccional efectiva. Lima: Palestra, 2007. pp. 231232. 
menester establecer qué ponderación se le asignará a cada uno de ellos para una adecuada aplicación de las normas por parte del juez, quien debe elegir el mejor mecanismo de solución en resguardo de los derechos pretendidos por las partes ${ }^{24}$. En atención a lo anterior, esta problemática se puede presentar -como se verá más adelante- en el caso en que el juicio tributario se prolongue por un tiempo que no resulta razonable frente a los plazos establecidos en cada una de las etapas del proceso.

En el caso de Chile, la fuente legal de la tutela jurisdiccional se encuentra radicada en el artículo 19 n 3 de la Constitución Política de la República, constituyendo, en sí misma, un derecho fundamental que incide principalmente en su efectiva protección en un proceso civil. Sin embargo, en una primera aproximación considerando la literalidad del texto, se podría sostener que el artículo 19 n 3 inciso quinto se encuentra ligado a la idea de argumentación, pero no a la efectividad, generando un grado de incertidumbre frente al derecho a ser juzgado en un plazo razonable. En el caso de Brasil, si se revisa el n 54 del artículo 5 de la Constitución Política del año 1988, se garantiza a los litigantes de un procedimiento judicial o administrativo, un proceso contradictorio y amplia defensa con los medios y recursos inherentes a la misma, sin embargo, dicha disposición no precisó si en el ejercicio de la defensa tendría relevancia la duración del proceso.

La falta de regulación en el derecho interno sobre la razonabilidad del plazo para ser juzgado, no inhibe la aplicación de aquellas normas que derivan del derecho internacional, incorporadas a través de convenios o tratados, debidamente ratificados por los Estados, destinadas a establecer límites para la duración de un juicio. Así, la mayoría de los países de la región tienen en común el respeto de los tratados internacionales ratificados por ambos países. En el caso de Brasil, el párrafo $2^{\circ}$ de la Constitución indica que " $2^{\circ}$ Os direitos e garantias expressos nesta Constituição não excluem outros decorrentes do regime e dos princípios por ela adotados, ou dos tratados internacionais em que a República Federativa do Brasil seja parte". Asimismo, el párrafo $3^{\circ}$ del artículo 5 indica que los tratados y convenciones internacionales sobre derechos humanos se aprueban en cada Cámara del Congreso Nacional en dos rondas, por tres quintos de los votos de los miembros respectivos, siendo equivalentes a las enmiendas constitucionales, es decir, tienen estatuto constitucional ${ }^{25}$, lo que también ha sido ratificado por la jurisprudencia de la Suprema Corte brasileña ${ }^{26}$. Por lo demás, la Corte Interamericana

\footnotetext{
24 FAÚNDEZ-UGALDE, Antonio. Tutela jurisdiccional efectiva y derecho tributario: ¿Una tensión permanente en el procedimiento de reclamación por vulneración de derechos?. Revista de Estudios Tributarios, n. 5, pp. 207-224. 2011. DOI: https://revistas.uchile.cl/index.php/RET/article/view/41137/42676.

25 ROZNAI, Yaniv; KREUZ, Letícia. Conventionality control and Amendment 95/2016: a Brazilian case of unconstitutional constitutional amendment. Revista de Investigações Constitucionais, vol. 5, n. 2, pp. 35-56. 2018. DOI: 10.5380/rinc.v5i2.57577.

26 MENDES, Gilmar Ferreira; BRANCO, Paulo Gustavo Gonet. Curso de direito constitucional. 9. ed. São Paulo: Saraiva, 2014. p. 130.
} 
de Derechos Humanos ha reconocido la posibilidad del control convencional de las normas de los países que violan las convenciones regionales ${ }^{27}$.

En Chile, una norma similar se encuentra en el inciso segundo del artículo 5 de la Constitución: "El ejercicio de la soberanía reconoce como limitación el respeto a los derechos esenciales que emanan de la naturaleza humana. Es deber de los órganos del Estado respetar y promover tales derechos, garantizados por esta Constitución, así como por los tratados internacionales ratificados por Chile y que se encuentren vigentes". Dichas disposiciones dejan de manifiesto la obligatoriedad en el respeto de los convenios internacionales ratificados por los países, como es el caso de la Convención Americana de Derechos Humanos (CADH), ratificada por Chile el 8 de octubre de 1990 y el 7 de septiembre de 1992, por Brasil. En tal caso, la Convención, en sí misma, constituye una contribución a la dogmática del derecho a la tutela judicial desde el momento que incorpora derechos y garantías procesales no directamente reconocidos en la Carta Fundamental de un país, y aporta nuevas perspectivas de interpretación de derechos y garantías sí reconocidos por el derecho interno ${ }^{28}$.

La referida CADH declara en el no 1 del artículo 8 que: "Toda persona tiene derecho a ser oída, con las debidas garantías y dentro de un plazo razonable, por un juez o tribunal competente, independiente e imparcial, establecido con anterioridad por la ley, en la sustanciación de cualquier acusación penal formulada contra ella, o para la determinación de sus derechos y obligaciones de orden civil, laboral, fiscal o de cualquier otro carácter". Por lo tanto, aplicar un criterio conforme a la razonabilidad del plazo para ser juzgado, puede encontrar sustento en lo establecido en el no 1 del artículo 8 de la CADH, por

27 ROZNAI, Yaniv; KREUZ, Letícia. Conventionality control and Amendment 95/2016: a Brazilian case of unconstitutional constitutional amendment. Revista de Investigações Constitucionais, vol. 5, n. 2, pp. 35-56. 2018. DOI: 10.5380/rinc.v5i2.57577; CONTESSE, Jorge. The International Authority if the Inter-American Court of Human Rights: a critique of the conventionality control doctrine. The International Journal of Human Rights, vol. 22, n. 9, pp.1168-1191. 2018. Disponible en: https://ssrn.com/abstract=3078268; OSWALDO, Ruiz-Chiriboga. The Conventionality Control: Examples of (Un)Successful Experiences in Latin America. Inter-American and European Human Rights Journal, vol. 3, n. 1-2, p. 200. 2010. Disponible en: https://ssrn. com/abstract=1929887; DULITZKY, Ariel E. An inter-american constitutional court? The invention of the conventionality control by the inter-american court of human rights. Texas International Law Journal, vol. 50, n. 1, p. 45-94. 2015. Disponible en: https://law.utexas.edu/faculty/publications/2015-An-Inter-American-Constitutional-Court-The-Invention-of-the-Conventionality-Control-by-the/download; SAGÜÉS, Nestor Pedro. Nuevas fronteras del control de convencionalidad: el reciclaje del derecho nacional y el control legisferante de convencionalidad. Revista de Investigações Constitucionais, Curitiba, vol. 1, n. 2, p. 23-32. 2014. DOI: http://dx.doi.org/10.5380/rinc.v1i2.40509; HERNÁNDEZ-MENDIBLE, Victor Rafael. El control de convencionalidad como expresión del control de constitucionalidad: originalidad y desaciertos. Revista de Investigações Constitucionais, Curitiba, vol. 2, n. 3, p. 137-168. 2015. DOI: http://dx.doi.org/10.5380/rinc.v2i3.44532. LEAL, Mônia Clarissa Hennig; ALVES, Felipe Dalenogare. O controle de convencionalidade e o Judiciário brasileiro: a sua aplicação pelo Tribunal Superior do Trabalho como forma de proteger a dignidade da mão-de-obra (vedação de terceirização de atividade- m) no case Carneiro Távora v. Telemar Norte Leste e Contax. Revista de Investigações Constitucionais, Curitiba, vol. 4, n. 1, p. 109-128. 2017. DOI: 10.5380/rinc. v4i1.48212.

28 PALOMO, Diego. Aportación de la Convención Americana de Derechos Humanos a la perspectiva chilena de la dogmática procesal del derecho a la tutela judicial. Un apoyo en dos fallos: casos Barrios Altos y Castillo Petruzzi. Revista lus Et Praxis, Talca, vol. 8, n. 2, 2002. DOI: http://dx.doi.org/10.4067/S0718-00122002000200009. 
remisión que hacen los artículos 5 n 54 de la Constitución Política de Brasil y el artículo $19 n^{\circ} 3$ de la Constitución Política de la República de Chile. Sin embargo, el problema se presenta en los casos en que el derecho para ser juzgado dentro de un plazo razonable reconocido en la $\mathrm{CADH}$, entra en colisión con una norma interna de derecho material, como sería el caso de la autoridad administrativa que decide ejercer su acción de fiscalización dentro de un plazo que su derecho interno lo ampara, pero excede la razonabilidad de declara la CADH. En otras palabras, el plazo que otorgue el derecho interno para el ejercicio de la acción fiscalizadora en la determinación de diferencias impositivas, podría ser considerado como no razonable si se suma todo el plazo que puede transcurrir, en sede jurisdiccional, frente a la impugnación del acto administrativo.

Para resolver la interrogante anterior, se debe hacer presente que el derecho a la efectividad de la tutela jurisdiccional debe atender al derecho material. Siendo así, es dable concluir que el derecho a la efectividad debe estar ligado a técnicas procesales capaces de dar respuestas adecuadas a las necesidades que de él provienen. Sin embargo, en este caudal de técnicas procesales el juez encontrará dificultades en la aplicación del derecho en los casos en que se presenten antinomias de normas, caso en el cual, los mecanismos de solución no pueden obviar la efectiva tutela jurisdiccional. Se insiste en que la tutela jurisdiccional constituye, en sí misma, un derecho fundamental que incide principalmente en su efectiva protección en un proceso. Es por esta razón que en la esfera de aplicación de las normas entre el derecho material y la efectiva tutela jurisdiccional, existirá una tensión permanente, en donde el juez deberá valorar entre los distintos mecanismos procesales, cuál resultará más efectivo en el otorgamiento de la tutela de los derechos que las partes del proceso han invocado. Marinoni ${ }^{29}$ indica que el proceso, frente a determinada construcción legal, puede no constituir una técnica capaz de responder efectivamente al derecho material; esta tensión de las normas puede ocurrir, por ejemplo, entre el trámite de admisibilidad de una acción -como técnica procesal- y la falta de fundamentos de la misma.

\section{MECANISMOS DE SOLUCIÓN FRENTE A LA COLISIÓN NORMATI- VA}

Como primer alcance en la búsqueda de una solución al problema, lo esencial es que las técnicas procesales de alguna forma deberán siempre adaptarse a las diferentes pretensiones de tutela de las partes del proceso vinculadas con el derecho material en cuestión, lo que permitirá la efectividad del proceso y, consecuencialmente, su concordancia con el derecho fundamental a la tutela jurisdiccional efectiva. Así por ejemplo, si la acción del contribuyente en contra de un acto de la autoridad fiscalizadora es

29 MARINONI, Luiz. Derecho fundamental a la tutela jurisdiccional efectiva. Lima: Palestra, 2007. p. 177. 
presentada fuera del plazo legal para hacerlo, la técnica procesal consistirá en la declaración de inadmisibilidad del reclamo como forma de establecer una tutela jurisdiccional efectiva respecto de la pretensión del órgano fiscalizador. La misma tensión de normas se presentará si la acción no es presentada cumpliendo las formalidades que establece la ley.

Sin perjuicio de que la tutela jurisdiccional abarca todo tipo de derechos, la tensión entre las normas revestirá mayor importancia cuando el derecho fundamental objeto del reclamo colisiona con la tutela jurisdiccional efectiva considerada, también, como un derecho fundamental. Esta situación debe ser apreciada por el juez caso a caso considerando los derechos fundamentales en pugna.

Aldunate $^{30}$ sintetiza distintas posiciones que buscan un mecanismo de solución a la colisión de normas: una primera solución se enmarca en la idea de establecer un orden de prelación o jerarquía determinable en abstracto, entre los diferentes derechos, idea que ha sido asimilada a la doctrina de los preferred rights de origen norteamericano. Se identifica en esta categoría el argumento de preferencia que debe dársele a aquellos derechos fundamentales que no sean renunciables para su titular (en especial, por estar asegurados en resguardo de la dignidad personal); a aquellos que posibilitan la realización de otros que devienen en posteriores, y por tanto, menos importantes que los primeros; a aquellos que cuentan con un positivo índice de garantización, reconocible a partir de la garantía otorgada vía acciones que ampara la Constitución; a aquellos cuya pérdida o supresión impacte en el ámbito institucional de modo más relevante; a aquellos derechos denominados "fines" en relación a los derechos "medios" para lograr esos fines y, por último, la preferencia que debe darse a aquel derecho que tienda a la mayor dignidad humana. Se ubican en esta postura a los autores Ruiz-Tagle y Cea Egaña.

Otra postura radica en la idea de ponderación de derechos en el caso concreto (balacing test) posición que implica que serán las circunstancias del caso las que aportarán los elementos determinantes de la preferencia que deba darse a un derecho por sobre otro, pero sólo en ese caso. La posibilidad de resolver la colisión de derechos por la vía de la ponderación se encuentra íntimamente vinculada a una concepción de derechos como principios, y es propuesta por Alexy con referencias al pensamiento de Dworkin. Alexy ${ }^{31}$ expresa que en las circunstancias específicas de la hipótesis, es posible establecer entre los principios una relación de precedencia condicionada, con precisa indicación de las condiciones para que un precepto preceda a otro. Puede ocurrir,

30 ALDUNATE, Eduardo. Derechos Fundamentales. Santiago: Legal Publishing, 2008. pp. 269 a 280; ALDUNATE, Eduardo. La colisión de derechos fundamentales. Revista Derecho y Humanidades, n. 11, pp. 69-78. 2005. DOI: https://revistas.uchile.cl/index.php/RDH/article/view/17052.

31 ALEXY, Robert. Teoría de los derechos fundamentales. España: Centro de Estudios Constitucionales. 1993. pp. 90 y 91. 
por eso, que, en otras condiciones, la precedencia se invierta. Agrega el mismo autor que el conflicto entre derechos fundamentales debería ser solucionado a través de un mecanismo de ponderación de los intereses opuestos. Explica este autor que en esta ponderación, de lo que se trata es determinar cuál de los intereses, abstractamente del mismo rango, posee mayor peso en el caso concreto; de esta forma, si la ponderación da como resultado que los intereses del reclamante, que se oponen a la intervención, tienen en el caso concreto un peso manifiestamente mayor que el de aquel interés a cuya preservación está dirigida la medida estatal, entonces la intervención viola el principio de proporcionalidad y, con ello, el derecho fundamental.

La tercera postura que sintetiza Aldunate es la idea de la armonización, concordancia práctica o del equilibrio adecuado. Para esta postura no se busca encontrar el criterio que permita a un derecho primar sobre otro, ni aún en el caso concreto, sino que debe buscarse una solución que permita lograr un óptimo de protección para los derechos que se enfrentan. Explica Aldunate que esta idea de armonización o concordancia práctica puede ser considerada, en sus efectos, una variante de la ponderación a la que se le suma el elemento teológico de buscar la óptima protección de los derechos en conflicto.

Finalmente, Aldunate considera y critica las diversas soluciones propuestas, planteando las siguientes hipótesis: la tesis de que no hay una solución general, sino que la Constitución distingue entre diversos derechos, de manera que las colisiones deben solucionarse de manera diversa según los derechos alegados; $y$, por otra parte, la tesis de que el uso constitucional de expresiones como ejercicio legítimo y restablecimiento del imperio del derecho implican que a nivel constitucional no existen criterios que permitan resolver las colisiones de derechos, sino que hay una remisión a las normas de nivel subconstitucional, en las que los jueces deberían hallar los criterios de solución so pena de verse abocados a crear derecho, para lo que no están autorizados.

Aldunate $^{32}$ se plantea la pregunta: ¿qué sucede cuando la antinomia se presenta entre el derecho fundamental de la tutela jurisdiccional efectiva y una norma inconstitucional? Al respecto, aborda dos hipótesis de solución: o bien, aceptar la posibilidad de que el juez prescinda de la ley inconstitucional y sea leal a la Constitución, o bien, mientras no exista un tribunal competente que declare la inconstitucionalidad de una ley, el juez se obliga a aplicar las leyes inconstitucionales.

Considerando las hipótesis anteriores, surge la siguiente inquietud: ¿frente a la colisión de una norma de derecho tributario material con un derecho fundamental, mientras no se declare la inconstitucionalidad de la primera, implica atentar contra la tutela jurisdiccional efectiva? Siguiendo a Aldunate $^{33}$, si existe un tribunal con com-

\footnotetext{
32 ALDUNATE, Eduardo. Derechos Fundamentales. Santiago: Legal Publishing, 2008. p. 203.

33 ALDUNATE, Eduardo. Derechos Fundamentales. Santiago: Legal Publishing, 2008. pp. 203 y 204.
} 
petencia para declarar inconstitucional un precepto legal a un caso en concreto, no soluciona la antinomia normativa, sino que dicha declaración tiene por finalidad impedirla. En este sentido, un juez perfectamente puede resolver dicha colisión, quedando la posibilidad que la referida aplicación de las normas sea revisada por los tribunales superiores. Por lo tanto, el pronunciamiento oportuno del juez de la instancia sobre la antinomia de normas, implica la protección efectiva de la tutela jurisdiccional.

\section{TRES SENTENCIAS}

El problema de colisión de derechos fundamentales con normas de derecho tributario material ha sido un tema discutido en la jurisprudencia chilena de los últimos años. En el caso "Industrial Molina Limitada con Servicio de Impuestos Internos" ${ }^{\text {"34 dio }}$ paso a una de las primeras sentencias en establecer la primacía de los derechos fundamentales reconocidos en la CADH por sobre normas de derecho material en el ámbito tributario. El conflicto se posicionaba en la prescripción de la acción de cobro de la autoridad fiscalizadora, en atención a que había transcurrido más de 6 años desde la presentación de la acción del contribuyente y la fecha de la notificación de la sentencia de primera instancia. La sentencia declaró en lo medular: "que las normas constitucionales y de derecho internacional exigen que la acción de la justicia sea rápida y oportuna, tanto en escuchar a los justiciables como en resolver los problemas planteados, sean ellos del ámbito civil o del penal. En tal perspectiva, si bien estos sentenciadores comparten que la presentación del reclamo basta para suspender el curso de la prescripción que consagra el Código Tributario, no pueden aceptar, en razón de la antedicha normativa -preferentemente integrada, en lo internacional, por el pacto de San José de Costa Rica y por el Pacto Internacional de Derechos Civiles y Políticos de las Naciones Unidas, además del artículo $5^{\circ}$ de la Carta Política, en lo nacional-, que tal suspensión opere incluso por un período mayor que el asignado por la legislación para la prescripción adquisitiva extraordinaria, esto es, en la práctica de manera indefinida". La colisión normativa es evidente, estableciendo una primacía de la CADH por sobre el derecho interno. Si bien, se presentaron dos votos discidentes de la sentencia, éstos plantearon rechazar la defensa del contribuyente por "la carencia de una regla de aplicación general entregada por el legislador, la aplicación del principio al que se recurre ha de ser consecuencia de las circunstancias del caso, esto es, resultado de hechos que obliguen a entender que ha tenido lugar una dilación inexcusable".

34 Sentencia Corte Suprema de fecha 14 de abril de 2014, "Industrial Molina Limitada con Servicio de Impuestos Internos", rol n 5.165-2013. 
Un año después del caso anterior, en la causa "Distribuidora don Francis S.A. con Servicio de Impuestos Internos" 135 , la Corte Suprema rechazó la defensa del contribuyente quien planteaba que la acción del Fisco estaba prescrita porque habían transcurrido 11 años desde la sentencia de primer grado, contraviniendo el no 1 del artículo 8 de la CADH. La Corte sustentó su sentencia en que "durante el tiempo transcurrido entre el 6 de diciembre de 2007, fecha en que la Corte de San Miguel ordenó reponer la causa al estado de proveer el reclamo, y la fecha en que éste se acogió a tramitación, la prescripción del artículo 200 del Código Tributario se encontraba suspendida, con ocasión del reclamo presentado por el contribuyente"; y, concluye: "la suspensión de la prescripción constituye un beneficio establecido por la ley a favor de determinadas personas, que a diferencia de la interrupción, no hace perder el tiempo de prescripción sino que ésta detiene su curso mientras subsista la causa que la produce. Desaparecida ella, continúa corriendo la prescripción, por lo que el tiempo se añadirá al que corra con posterioridad". Este es un claro caso en donde en la decisión del asunto controvertido primó el derecho interno por sobre la $\mathrm{CADH}$. Sin embargo, en la misma sentencia el voto de minoría declaró la procedencia en reconocer los derechos de la $\mathrm{CADH}$ por sobre el derecho interno. En efecto, el voto discidente aceptó la "prescripción de la acción de cobro, porque, en su concepto, consideraciones afincadas en el respeto a las normas constitucionales y de derecho internacional exigen que la acción de la justicia sea rápida y oportuna, tanto en escuchar a los justiciables como en resolver los problemas planteados, sean ellos del ámbito civil o del penal, debiendo resolverse el conflicto en un plazo razonable"; y concluye: "no puede aceptar, en razón de la antedicha normativa -preferentemente integrada, en lo internacional, por el Pacto de San José de Costa Rica y por el Pacto Internacional de Derechos Civiles y Políticos de las Naciones Unidas, además del artículo $5^{\circ}$ de la Carta Política, en lo nacional-, que el cobro se extienda por más una década, plazo considerado desde la data de exigibilidad de los impuestos hasta la fecha de expedición de esta sentencia; lo que aparece como contrario a toda lógica y por cierto a las citadas disposiciones internacionales, con evidente conculcación de los derechos del contribuyente reconocidos por tales normas. Resulta contradictorio que la máxima prescripción que contempla nuestro Código Civil opera al vencimiento del término de diez años y, en cambio, la prescripción en materia tributaria pueda requerir mayor plazo".

Una tercera sentencia a destacar es el caso "Fernando Echavarri Borssotto con Servicio de Impuestos Internos"136, en donde la Corte Suprema nuevamente estuvo por acoger la prescripción de la acción del Fisco al haber transcurrido mas de dos décadas desde la presentación de la reclamación. La sentencia indicó que el caso debía

35 Sentencia Corte Suprema de fecha 10 de septiembre de 2015, “Distribuidora don Francis S.A. con Servicio de Impuestos Internos", rol no 16.644-2014.

36 Sentencia Corte Suprema de fecha 10 de enero de 2017,"Fernando Echavarri Borssotto con Servicio de Impuestos Internos", rol n 15.929-2016. 
considerar "Ia forma en que las disposiciones del derecho interno se relacionan con las normas constitucionales y de derecho internacional citadas, pues el respeto de estas últimas, exige que la acción de la justicia sea rápida y oportuna, tanto en escuchar a los justiciables, como en zanjar los problemas puestos en su conocimiento, sean ellos del ámbito civil o penal, debiendo resolverse el conflicto en un plazo razonable, esto es, ajustado a la razón. En tal perspectiva, si bien la conjunción de los artículos 201 incisos $2^{\circ}$ y $3^{\circ}$ dejan en claro que la presentación del reclamo basta para suspender el curso de la prescripción que consagra el Código Tributario y que ese estado se mantiene, de acuerdo con su inciso final, mientras los impuestos no pueden girarse, ya sea en primera instancia por disposición de la ley o en alzada a petición del reclamante (artículo 24 inciso $2^{\circ}$ y 147), no es posible aceptar, en razón de la antedicha normativa -preferentemente integrada, en lo internacional, por el pacto de San José de Costa Rica y el artículo $5^{\circ}$ de la Carta Política, en lo nacional-, que tal suspensión opere, en la práctica, de manera indefinida, deviniendo la acción de cobro del Fisco, en los hechos, en imprescriptible, sin fundamento legal". Esta sentencia también presentó dos votos de minoría, los que sostuvieron que, si bien, "la Convención Americana de Derechos Humanos, es directamente aplicable por estar incorporada al ordenamiento jurídico nacional, se trata de un concepto jurídico indeterminado, que carece de precisión legislativa dentro de los cuales se encuadre su aplicación, esto es, no contiene la determinación de lo que debe entenderse como un tiempo razonable para justificar un juzgamiento".

De acuerdo con las sentencias anteriores, la discusión aún no es pacífica, sin perjuicio de que hay una tendencia en aceptar la primacía de la CADH como forma de solucionar colisiones normativas con el derecho interno. En tal problemática, el mecanismo de solución ha sido aceptar la posibilidad de que el juez prescinda de la ley interna y sea leal a los derechos fundamentales recogidos por la $\mathrm{CADH}$, sin necesidad de obtener, previamente, alguna declaración de inconstitucionalidad, lo que responde una protección efectiva de la tutela jurisdiccional.

\section{CONCLUSIONES}

Un proceso que ofrezca garantías mínimas para las partes no puede quedar limitado solamente a la aplicación de las normas de derecho material. De acuerdo con ello, el mecanismo efectivo de tutela, como derecho fundamental en sí mismo, debe considerar una complementación con el derecho tributario material, no desconociendo la posibilidad de generar colisiones normativas. Dentro de las formas de solución de dichas colisiones entre una norma de derecho tributario material y un derecho fundamental, adherimos a la propuesta de Aldunate, esto es, aceptar la posibilidad de que el juez prescinda de la ley inconstitucional y sea leal a la Constitución. En tal sentido, si existe un tribunal con competencia para declarar inconstitucional un precepto legal a un caso en concreto, no soluciona la antinomia normativa, sino que dicha declaración 
tiene por finalidad impedirla. Por lo tanto, un juez puede resolver una colisión normativa sin necesidad de esperar una declaración de inconstitucionalidad de una norma de derecho tributario material, como se presentó en los casos chilenos "Industrial Molina Limitada con Servicio de Impuestos Internos" y "Fernando Echavarri Borssotto con Servicio de Impuestos Internos", lo que, perfectamente, puede tener aplicación en el ordenamiento jurídico brasileño.

\section{REFERENCIAS}

ALDUNATE, Eduardo. Derechos Fundamentales. Santiago: Legal Publishing, 2008.

ALDUNATE, Eduardo. La colisión de derechos fundamentales. Revista Derecho y Humanidades, n. 11, pp. 69-78. 2005. DOl: https://revistas.uchile.cl/index.php/RDH/article/view/17052.

ALEXY, Robert. Teoría de los derechos fundamentales. España: Centro de Estudios Constitucionales. 1993.

CHIOVENDA, Giuseppe. Istituzioni di diritto processuale civile. Napoli: Jovene. 1960.

CONTESSE, Jorge. The International Authority if the Inter-American Court of Human Rights: a critique of the conventionality control doctrine. The International Journal of Human Rights, vol. 22, n. 9, pp.1168-1191. 2018. Disponible en: <https://ssrn.com/abstract=3078268>.

DE OLIVEIRA, Carlos. El derecho a la tutela jurisdiccional efectiva desde la perspectiva de los derechos fundamentales. Revista de Derecho, Valdivia, vol. 22, n. 1, pp. 185-201. 2009. DOI: <http://dx.doi.org/10.4067/S0718-09502009000100009>.

DE OLIVEIRA, Carlos. Teoría y práctica de la tutela jurisdiccional. Lima: Communitas, 2008.

DULITZKY, Ariel E. An inter-american constitutional court? The invention of the conventionality control by the inter-american court of human rights. Texas International Law Journal, vol. 50, n. 1, p. 45-94. 2015. Disponible en: <https://law.utexas.edu/faculty/publications/2015-An-Inter-American-Constitutional-Court-The-Invention-of-the-Conventionality-Control-by-the/ download>.

FAÚNDEZ-UGALDE, Antonio. Tutela jurisdiccional efectiva y derecho tributario: ¿Una tensión permanente en el procedimiento de reclamación por vulneración de derechos?. Revista de Estudios Tributarios, n. 5, pp. 207-224. 2011. DOI: <https://revistas.uchile.cl/index.php/RET/article/ view/41137/42676>.

GONZÁLEZ, Jesús. El derecho a la tutela jurisdiccional. Madrid: Civitas, 1984.

HENRÍQUEZ, Miriam. Análisis jurisprudencial de la aplicación de los tratados de derechos humanos en recursos de protección (1989 - 2010). Estudios Constitucionales, Talca, vol. 8, n. 2, pp. 745-762. 2010. DOI: <http://dx.doi.org/10.4067/S0718-52002010000200022>. 
HERNÁNDEZ-MENDIBLE, Victor Rafael. El control de convencionalidad como expresión del control de constitucionalidad: originalidad y desaciertos. Revista de Investigações Constitucionais, Curitiba, vol. 2, n. 3, p. 137-168. 2015. DOI: <http://dx.doi.org/10.5380/rinc.v2i3.44532>.

LEAL, Mônia Clarissa Hennig; ALVES, Felipe Dalenogare. O controle de convencionalidade e o Judiciário brasileiro: a sua aplicação pelo Tribunal Superior do Trabalho como forma de proteger a dignidade da mão-de-obra (vedação de terceirização de atividade- m) no case Carneiro Távora v. Telemar Norte Leste e Contax. Revista de Investigações Constitucionais, Curitiba, vol. 4, n. 1, p. 109-128. 2017. DOI: <10.5380/rinc. v4i1.48212>.

MARINONI, Luiz. Derecho fundamental a la tutela jurisdiccional efectiva. Lima: Palestra, 2007. MARINONI, Luiz. Teoría geral do proceso. São Paulo: Revista dos Tribunais. 2006.

MENDES, Gilmar Ferreira; BRANCO, Paulo Gustavo Gonet. Curso de direito constitucional. 9. ed. São Paulo: Saraiva, 2014. p. 130.

OSWALDO, Ruiz-Chiriboga. The Conventionality Control: Examples of (Un)Successful Experiences in Latin America. Inter-American and European Human Rights Journal, vol. 3, n. 1-2, p. 200. 2010. Disponible en: $<$ https://ssrn.com/abstract=1929887>.

PALOMO, Diego. Aportación de la Convención Americana de Derechos Humanos a la perspectiva chilena de la dogmática procesal del derecho a la tutela judicial. Un apoyo en dos fallos: casos Barrios Altos y Castillo Petruzzi. Revista lus Et Praxis, Talca, vol. 8, n. 2, 2002. DOI: <http://dx.doi. org/10.4067/S0718-00122002000200009>.

PÉREZ, Álvaro; SILVA, Oscar. El imperativo de transparencia patrimonial del deudor como requisito funcional para una ejecución civil eficiente. Revista lus Et Praxis, Talca, vol. 15, n. 2, pp. 79-115. 2009. Disponible en: <http://www.revistaiepraxis.cl/index.php/iepraxis/article/view/180/173>.

PROTO, Andrea. Lezioni di diritto processuale civile. Napoli: Jovene. 2006.

ROZNAI, Yaniv; KREUZ, Letícia. Conventionality control and Amendment 95/2016: a Brazilian case of unconstitutional constitutional amendment. Revista de Investigações Constitucionais, vol. 5, n. 2, pp. 35-56. 2018. DOI: <10.5380/rinc.v5i2.57577>.

SAGÜÉS, Nestor Pedro. Nuevas fronteras del control de convencionalidad: el reciclaje del derecho nacional y el control legisferante de convencionalidad. Revista de Investigações Constitucionais, Curitiba, vol. 1, n. 2, p. 23-32. 2014. DOI: <http://dx.doi.org/10.5380/rinc.v1i2.40509>.

VALLESPÍN, David. El modelo constitucional de juicio justo en el ámbito del proceso civil. Barcelona: Atelier, 2002. 